\title{
Do personal computers make doctors less personal?
}

\author{
JAN-JOOST RETHANS， PAUL HÖPPENER，GEORGE WOLFS，JOS DIEDERIKS
}

\begin{abstract}
Ten months after the installation of a computer in a general practice surgery a postal survey (piloted questionnaire) was sent to 390 patients. The patients' views of their relationship with their doctor after the computer was introduced were compared with their view of their relationship before the installation of the computer. More than $96 \%$ of the patients $(n=263)$ stated that contact with their doctor was as easy and as personal as before. Most stated that the computer did not influence the duration of the consultation. Eighty one patients $(30 \%)$ stated, however, that they thought that their privacy was reduced.

Unlike studies of patients' attitudes performed before any actual experience of use of a computer in general practice, this study found that patients have little difficulty in accepting the presence of a computer in the consultation room. Nevertheless, doctors should inform their patients about any connections between their computer and other, external computers to allay fears about a decrease in privacy.
\end{abstract}

\section{Introduction}

Though computers have penetrated almost all layers of society and most people are familiar with the sight of them, they are not yet common in general practitioners' consulting rooms. Cruickshank investigated the attitude of two groups of patients towards computers in general practice. ${ }^{\prime}$ The first group had been confronted once with a computer in the consulting room; the second group had not. Over half of each group believed that with a computer around the personal touch of the doctor would be lost.

Pringle et al investigated their patients' views about the presence of a personal computer before installing a computer in the surgery. ${ }^{2}$ They reported that $31 \%$ of patients feared that confidentiality of information would be reduced. These studies, however, dealt with patients who had no experience of their own general practitioner using a computer.

In this study we explored patients' opinions about their contacts with their own general practitioners when a computer was present in the consulting room. A questionnaire was given to those patients who were confronted with the computer during their contacts with their doctor during the 10 months from August 1986 onwards. The purpose of the study was to determine the opinion of patients about surgery contact with their own general practitioner when he used a computer compared with their opinion of their former contacts with this doctor.

\section{Patients and methods}

So that we could develop a structured questionnaire six patients were interviewed by a research assistant who did not know the patients. The practice medical secretary was asked to select these patients. The six patients were representative of several age groups and were willing to talk about their contact with their doctor. The tapes of these interviews were transcribed and items selected from the transcripts for the structured questionnaire. These concentrated on personal contact, privacy, and influence on the duration of the consultation. Using these items, we made 16 statements, seven positively and nine negatively stated, which we ordered randomly. Patients were asked 
to fill in whether they "completely disagreed," "partly disagreed," "partly agreed," or "completely agreed" with the statements. The questionnaire thus worked on a four point Likert scale. ${ }^{3}$ The questionnaire was piloted among patients who consulted their doctor. When they had completed the questionnaire the patients were asked about the clarity and unambiguity of the statements. Their comments helped us to construct the final version.

As we were interested in the opinions of those patients who had contacted their practitioner before and after the installation of the computer, we selected only patients who $(a)$ had consulted their doctor before the introduction of the computer in the surgery for at least a year; $(b)$ had consulted their doctor at least once after the introduction of the computer and $(c)$ were aged over 12 years. Patients were selected from a register of al patients who visited the practice on Monday, Wednesday, and Friday mornings from 27 March 1987 until 20 May 1987 (excluding two weeks when the doctor was on holiday). Thus 390 patients were selected who met our inclusion criteria.

As patients tend to give answers in agreement with their doctors ${ }^{4}$ we authorised the University of Limburg to distribute the questionnaire to the patients and receive the answers. In the covering letter the complete anonymity of the patients was emphasised, because of the evident need to handle this sort of information in this way and to minimise the nonrespondent bias, which was estimated to be high in view of other, published studies. ${ }^{12}$

In the practice studied a personal computer system, consisting of one computer and two terminals, had been in operation since August 1986. The whole surgery process was computerised and the doctors keyed in directly all information received from the patients. Consequently, not only administrative data (entered only at the first visit) but the whole clinical process (clinical notes) was recorded. The practice population consisted of 2900 patients, served by two doctors in the morning (surgery hours) and one in the afternoon and by two part time $(0.5)$ medical secretaries. The practice was in the city of Heerlen, a town with 72000 inhabitants in the south of The Netherlands.

\section{Results}

Of the 390 questionnaires posted, $270(69 \cdot 2 \%)$ were returned. Seven of these were not suitable for inclusion, four because the respondents did not want to cooperate in a research project and three because the respondents stated that they thought they had seen too little of their doctor and the computer. The 263 remaining questionnaires constituted $67 \cdot 4 \%$ of those posted. For these completed forms Crombach's $\alpha$, a measure of internal consistency, was $0 \cdot 76$. Table I shows the responses to the 16 statements in the questionnaire. The mean age of the respondents was 45 (range 12-87 (SD 18)), which was not significantly different from the age of the non-respondents.

Table II shows the number of surgery contacts that the patients had with their doctor after the computer had been installed. Thirty three patients had a personal computer themselves at home and 181 used a personal computer at work.

Nearly all of the patients (item 1: $92 \cdot 2 \%$ ) stated that contact with their doctor was as easy as before and especially that their contact was not less personal (item 6: 92·7\%). In general, they disagreed with the statement that patients wanting personal contact with their doctor should choose one without a computer (item 3: 90・1\%). They also disagreed with the statement that doctors who care about their patients should not install a computer (item 16: 95.9\%).

Most also denied that the time spent in the consulting room was longer (item 2: $86.7 \%$ ) than before the installation of the computer and disagreed that their doctor spent longer with them (item 10: 76.1\%). They disagreed that the time spent in the waiting room was shorter than before (item 4: $74 \cdot 5 \%)$.

With regard to the issue of privacy a minority agreed that it was now easier for others to obtain information from their personal files (item 8: 30.8\%) and most disagreed that their privacy was more secure than before the introduction of the computer (item 14:66.5\%). Patients seemed to think that with the computer their doctor got a picture of their medical history more quickly (item 5: 86.6\% agreed) but not that their doctor delivered better care (item 13: $84 \cdot 8 \%$ disagreed)

No significant correlation was found between the number of surgery contacts, age, and educational level and the patients' mean score on the questionnaire.

\section{Discussion}

Pringle reported that $31 \%$ of patients believed that with the computer the personal touch of the doctor would be lost; Cruick- shank reported an even higher figure. ${ }^{21}$ In Cruickshank's study more than half of the patients believed this. One of the most crucial issues in general practice is the belief or trust that patients have in their doctor. Bass et al studied outcome in several diseases common in general practice. ${ }^{5}$ They concluded that what influenced the outcome most was the agreement between the patient and the doctor about the disease, and subsequently the trust in their relationship.

TABLE I-Responses to items in the questionnaire in number (percentage) of patients $(n=263)$

\begin{tabular}{|c|c|c|c|c|c|}
\hline $\begin{array}{l}\text { Item } \\
\text { No }\end{array}$ & & $\begin{array}{c}\text { Completely } \\
\text { disagree }\end{array}$ & $\begin{array}{l}\text { Partially } \\
\text { disagree }\end{array}$ & $\begin{array}{c}\text { Partially } \\
\text { agree }\end{array}$ & $\begin{array}{l}\text { Completely } \\
\text { agree }\end{array}$ \\
\hline 1 & $\begin{array}{l}\text { I can talk as easily with my doctor now } \\
\text { that he uses a computer as I did } \\
\text { before }\end{array}$ & $3(1 \cdot 1)$ & $7(2 \cdot 7)$ & $86(32 \cdot 7)$ & $167(63 \cdot 5)$ \\
\hline 2 & $\begin{array}{l}\text { The consultation takes longer now } \\
\text { that my doctor uses a computer }\end{array}$ & $54(20 \cdot 5)$ & $174(66 \cdot 2)$ & $20(7 \cdot 6)$ & $15(5 \cdot 7)$ \\
\hline 3 & $\begin{array}{l}\text { Patients who want good personal } \\
\text { contact with their doctor should } \\
\text { choose a doctor without a computer }\end{array}$ & $114(43 \cdot 3)$ & $124(47 \cdot 1)$ & $10(3 \cdot 8)$ & $15(5 \cdot 7)$ \\
\hline 4 & $\begin{array}{l}\text { The waiting time before the } \\
\text { consultation has become shorter } \\
\text { since my doctor has used a } \\
\text { computer }\end{array}$ & $31(11 \cdot 8)$ & $165(62 \cdot 7)$ & $49(18 \cdot 6)$ & $18(6 \cdot 8)$ \\
\hline 5 & $\begin{array}{l}\text { I have noticed that since my doctor } \\
\text { has used a computer he gets a } \\
\text { quicker overview of my medical } \\
\text { files than he did before }\end{array}$ & $5(1.9)$ & $30(11 \cdot 4)$ & $99(37 \cdot 6)$ & $129(49 \cdot 0)$ \\
\hline 6 & $\begin{array}{l}\text { Since the introduction of the } \\
\text { computer in the practice contact } \\
\text { with my doctor has become less } \\
\text { personal }\end{array}$ & $119(42 \cdot 5)$ & $125(47 \cdot 5)$ & $12(4 \cdot 6)$ & $7(2 \cdot 7)$ \\
\hline 7 & $\begin{array}{l}\text { I do not like the idea of a doctor with a } \\
\text { computer }\end{array}$ & $151(57 \cdot 4)$ & $94(35 \cdot 7)$ & $14(5 \cdot 3)$ & $4(1.5)$ \\
\hline 8 & $\begin{array}{l}\text { Since the introduction of the } \\
\text { computer in the practice other } \\
\text { people get access to my medical } \\
\text { files more easily than they did } \\
\text { before }\end{array}$ & $64(24 \cdot 3)$ & $118(44.9)$ & $61(23 \cdot 2)$ & $20(7 \cdot 6)$ \\
\hline 9 & $\begin{array}{l}\text { I do not think my doctor would blame } \\
\text { the computer if he made a mistake } \\
\text { himself }\end{array}$ & $36(13 \cdot 7)$ & $70(26 \cdot 6)$ & $107(40 \cdot 7)$ & $50(19 \cdot 0)$ \\
\hline 10 & $\begin{array}{l}\text { Since he has used a computer my } \\
\text { doctor spends more time with me } \\
\text { during the consultation than he did } \\
\text { before }\end{array}$ & $26(9.9)$ & $174(66 \cdot 2)$ & $48(18 \cdot 3)$ & $15(5 \cdot 7)$ \\
\hline 11 & Since my doctor has used a computer & & & & \\
\hline & $\begin{array}{l}\text { I feel more like a mere number than } \\
\text { I did before }\end{array}$ & $127(48 \cdot 3)$ & $126(47 \cdot 9)$ & $7(2 \cdot 7)$ & $3(1 \cdot 1)$ \\
\hline 12 & $\begin{array}{l}\text { Computers make too many mistakes } \\
\text { to trust my medical files to them }\end{array}$ & $95(36 \cdot 1)$ & $156(59 \cdot 3)$ & $8(3.0)$ & $4(1 \cdot 5)$ \\
\hline 13 & $\begin{array}{l}\text { With a computer my doctor treats me } \\
\text { better than he did without a } \\
\text { computer }\end{array}$ & $52(19 \cdot 8)$ & $171(66 \cdot 5)$ & $29(11 \cdot 0)$ & $11(4 \cdot 2)$ \\
\hline 14 & $\begin{array}{l}\text { With my medical files in the computer } \\
\text { my privacy is more secure than it } \\
\text { was before }\end{array}$ & $29(11 \cdot 0)$ & $146(55 \cdot 5)$ & $70(26 \cdot 6)$ & $18(6.8)$ \\
\hline 15 & $\begin{array}{l}\text { Since he has had a computer my } \\
\text { doctor watches the screen rather } \\
\text { than me }\end{array}$ & $95(36 \cdot 1)$ & $143(54 \cdot 5)$ & $18 \quad(6 \cdot 8)$ & $7(2 \cdot 7)$ \\
\hline 16 & $\begin{array}{l}\text { Doctors who care about their patients } \\
\text { do not want a computer in their } \\
\text { practice }\end{array}$ & $138(52 \cdot 5)$ & $114(43 \cdot 4)$ & $6(2 \cdot 3)$ & $5(1 \cdot 9)$ \\
\hline
\end{tabular}

TABLE II-Number of surgery contacts in the presence of a computer

\begin{tabular}{lc}
\hline No of contacts & No $(\%)$ of patients $(n=263)$ \\
\hline $1-2$ & $86(32 \cdot 6)$ \\
$3-4$ & $104(39 \cdot 5)$ \\
$5-6$ & $55(20 \cdot 9)$ \\
$7-10$ & $9(3 \cdot 4)$ \\
$\geqslant 11$ & $9(3 \cdot 4)$ \\
\hline
\end{tabular}

Both Pringle and Cruickshank studied patients in general practice who had never consulted their own doctor in the presence of a computer. This study, however, dealt with patients who had had that experience. It seems that consultations with a doctor with a computer present change patients' opinions. From the answers to items $1,3,6,11$, and 16 it may be concluded that computers do not change the personal contact between the patient and the doctor to a 
large extent. The additional comments that $46(18 \%)$ of the 262 patients wrote down in reply to the questionnaire seem to confirm this. Of these 46 patients, 17 (37\%) made remarks like "nothing changed with the computer, my doctor is good"; "I do not care if there is a computer in the surgery." Seven (15\%) said that they clearly perceived that their doctor had a quicker overview of their medical files with the computer. Three $(6 \%)$ stated that their contact was even more personal than before because they could read what the doctor typed. Another three (6\%) stated that they felt their relationship with the doctor was more equal than before. The computer did not seem to affect the duration of consultations (items 2, 4, and 10).

As stated above, we did not find any important correlations between age, frequency of consultation, and educational level and the total score on this questionnaire. This differs from Cruickshank's results. ${ }^{1}$ We would ascribe this to the difference in experience with the computer in the surgery between her patients and our patients. The variables mentioned before do not differentiate any more between patients when all patients have had experience of the computer for some time.

Of serious concern is the finding that $66 \%$ of the patients disagreed with the statement that their privacy was more secure when their files were in the computer (item 14). In response to the statement that "with the computer it could be easier for others to get my medical files without any permission," however, $69 \%$ disagreed (item 8). Patients thus seem to have ambiguous feelings about this aspect. It could be that the word privacy is too heavily loaded for most people. The word has been used (and mostly in a negative context) in almost every discussion about computers in the past few years, and it could well be that this distorted the patients' view. This might explain the paradox between the answers to items 8 and 14 . Item 8 refers to a situation which is more familiar to patients and is easier to understand. As a result of the answers to statements 8 and 14 we have started to inform our patients that there is no connection between our computer and any computer or telephone line outside the practice.

How much were the findings of this study influenced by the non-respondents? At the start of this study we estimated, in view of previous reports, ${ }^{12}$ that a large group might not be willing to express their opinion in the questionnaire. We adopted a completely anonymous procedure for the patients. Because of this it was impossible for us to trace the non-respondents. We do not consider the $30 \%$ non-respondents to be a very large group. By age they did not differ systematically from those who did answer. We also looked at the number of patients who had left the practice after the introduction of the computer and compared this figure with that for the same period in the previous year. We found no difference. We are therefore inclined to conclude that the non-respondents did not substantially influence the results presented here. Another issue that might have influenced the results is the fact that this study was performed in only one practice. We understand, however, that we are the first practice in The Netherlands to use a computer in the extended way described above and we were unable to extend the study to include a general practice elsewhere in Europe that was comparable to ours.

The main conclusion of this study is that patients have little difficulty in accepting the presence of a computer in the consultation room. Another important conclusion is that personal computers do not make doctors seem less personal. It is still the personality of the doctor that makes him or her more or less personal to patients; the computer is merely a tool. We do advise, however, that doctors wishing to install a computer in their practice should inform their patients clearly about its connections with other computers in order to allay fears about a decrease in privacy.

We thank P Cuypers, V Kaiser, R Kocken, Y van Leeuwen, T RethansWillems, and P Wallace (London) for their help during the study. This study has been made possible by a grant from the Nederlands Huisarts Genootschap.

\section{References}

1 Cruickshank PJ. Computers in medicine: patients' attitudes. $f$ R Coll Gen Pract 1984;34:77-80. 2 Pringle M, Robins S, Brown G. The patient's view. Br Med f 1984;288:289-92.

3 Oppenheim AN. Questionnaire design and attitude measurement. London: Heinemann, 1966.

4 Woolley FR, Kane RL, Hughes CC, et al. The effects of doctor-patient communication on satisfaction and outcome of care. Soc Sci Med 1978;12:123-8.

5 Bass MJ, Buck C, Turner L, et al. The physician's actions and the outcome of illness in family practice. $\mathcal{F}$ Fam Pract 1986;23:43-7.

(Accepted l February 1988)

\section{ONE HUNDRED YEARS AGO}

ProfesSOR Humphry's recent Collective Investigation Report on Aged Persons, published in the JouRNAL, contains some very positive evidence on a matter which has already engaged the attention of moralists as well as physicians. "The opportunity for nutrition to do its restorative work was in nearly all provided by the faculty of 'good sleeping,' to which was commonly added its appropriate attendant, the habit of 'early rising.'" Thus there is a relation between early rising and longevity. No doubt many people will hastily seize upon the sentence just quoted, and employ it in edifying lectures or essays for the perusal of youth, or embody in it popular medical works. Important qualifications follow in Dr. Humphry's Report, but they are likely to be overlooked. Doubtless the habit of early rising is, in itself, healthy; most of all, it is a good sign of health when it evidently signifies rapid recovery from fatigue. Again, it usually denotes a strong will, the gift as a rule of a good physical constitution, or at least the safeguard of average bodily strength. Late risers are generally either invalids or persons of bad habits, idlers who are never free from other vices besides idleness. The nervous exhaustion which keeps a man wakeful throughout the small hours produces sleep late in the morning. This exhaustion is invariably due to one of several life-shortening influences, especially anxiety or indiscretion in diet or drink. Early rising is thus rather one effect of certain favourable influences, another result of which is longevity, than a cause of longevity. To turn a weakly man out of bed every morning at 7 o'clock will not prolong his life. It will be noted that by "good sleeping" Professor Humphry signifies quick sleeping, "that is, the reparative work which has to be done in sleep is done briskly and well." Here, again, we have an effect of a cause; but preventing a weakly subject from sleeping more than four or five hours nightly would not cause him to live long, but would rather tend to shorten his life. Equally important are Professor Humphry's observations which show that by "early" he does not entirely mean the time by the clock. The word "has a relative significance with reference to the time of going to bed. A person who retires to rest four hours after midnight and gets up at $10 \mathrm{~A} . \mathrm{M}$. may be strictly regarded as an 'early riser.'" Thus early rising is synonymous, in long life histories, with short sleeping, which means rapid recovery from fatigue, a sign of bodily strength. These scientific facts in no wise contradict the alleged value of early rising as a practice to be cultivated by all persons in good health. It is excellent as moral discipline, and eminently healthy as a matter of fact. Most persons will eat three meals daily. When a man gets up late those meals will probably follow each other at too short intervals to be wholesome. When he is an early riser it will probably be otherwise. He can enjoy a good breakfast, and by the time for his lunch or mid-day dinner he will have an honest appetite again.

(British Medical Fournal 1888;i:710.) 